\title{
Laboratory and Field-Based Evaluation of Short-Term Effort with Maximal Intensity in Individuals with Intellectual Disabilities
}

\author{
by \\ Judit Lencse-Mucha ${ }^{1}$, Bartosz Molik ${ }^{1}$, Jolanta Marszatek ${ }^{1}$, \\ Kalina Kaźmierska-Kowalewska², Anna Ogonowska-Słodownik ${ }^{3}$
}

\begin{abstract}
Results of previous studies have not indicated clearly which tests should be used to assess short-term efforts of people with intellectual disabilities. Thus, the aim of the present study was to evaluate laboratory and field-based tests of short-term effort with maximal intensity of subjects with intellectual disabilities. Twenty four people with intellectual disability, who trained soccer, participated in this study. The $30 \mathrm{~s}$ Wingate test and additionally an $8 \mathrm{~s}$ test with maximum intensity were performed on a bicycle ergometer. The fatigue index, maximal and mean power, relative maximal and relative mean power were measured. Overall, nine field-based tests were conducted: 5, 10 and $20 \mathrm{~m}$ sprints, a 20 m shuttle run, a seated medicine ball throw, a bent arm hang test, a standing broad jump, sit-ups and a hand grip test. The reliability of the $30 \mathrm{~s}$ and $8 \mathrm{~s}$ Wingate tests for subjects with intellectual disability was confirmed. Significant correlation was observed for mean power between the $30 \mathrm{~s}$ and $8 \mathrm{~s}$ tests on the bicycle ergometer at a moderate level $(r>0.4)$. Moreover, significant correlations were indicated between the results of laboratory tests and field tests, such as the $20 \mathrm{~m}$ sprint, the $20 \mathrm{~m}$ shuttle run, the standing long jump and the medicine ball throw. The strongest correlation was in the medicine ball throw. The $30 \mathrm{~s}$ Wingate test is a reliable test assessing maximal effort in subjects with intellectual disability. The results of this research confirmed that the $8 \mathrm{~s}$ test on a bicycle ergometer had a moderate correlation with the $30 \mathrm{~s}$ Wingate test in this population, thus, this comparison needs further investigation to examine alternativeness of the $8 \mathrm{~s}$ to $30 \mathrm{~s}$ Wingate tests. The non-laboratory tests could be used to indirectly assess performance in short-term efforts with maximal intensity.
\end{abstract}

Key words: anaerobic performance, physical fitness, intellectual disability, Wingate test.

\section{Introduction}

Laboratory aerobic endurance tests have been frequently used and described by researchers (Fernhall and Pitetti, 2001; Beynard at al., 2008; Pitetti at al., 2012). The level of peak aerobic power (VO2peak) has been well established in people with intellectual disability (ID) (Baynard et al., 2008). Previous studies have demonstrated that young subjects with ID had lower cardiovascular performance (Yarmer et al., 2000; Pitetti et al., 2012) and a higher level of body fat than their peers without ID (Wondra et al., 2000; Frey, 2004). People with ID also presented a lower level of physical activity compared to their peers without ID. Many studies demonstrated data concerning low physical fitness (Pittetti et al., 2012; Fernhall and Pitetti, 2001; Guerra et al., 2000;

\footnotetext{
1 - Department of Sport for People with Disabilities, Faculty of Physiotherapy, University of Physical Education in Warsaw, Poland.

2 - Department of Theory and Methodology in Teaching Movement of People with Disabilities Faculty of Physiotherapy, University of Physical Education in Warsaw, Poland.

3 - Department of Adapted Physical Activity Faculty of Physiotherapy, University of Physical Education in Warsaw, Poland.
} 
Jin-Ding et al., 2010). Low muscle power in individuals with ID was also showed (Pitetti and Boneh, 1995; Guerra et al., 2000; Fernhall, 1996; Horvat et al., 1999). Blomqvist et al. (2013) reported poor balance in people with this disability. Only the study of Chia et al. (2002) examined short time performance with maximal intensity in subjects with ID.

Intellectual disability is not a contraindication for high intensity anaerobic performance. People with ID participate in anaerobic-type training in the Special Olympics e.g. gymnastics, powerlifting, a $100 \mathrm{~m}$ run, basketball and soccer. Therefore, studies evaluating anaerobic capacity of people with ID could give a more complete picture of physical capabilities of this population.

The Wingate Anaerobic Test (WAnT) is the most popular high intensity test (Inbar et al., 1996). This test is used to determine peak power (PP), mean power (MP) and the fatique index (FI) while pedalling at maximum speed for $30 \mathrm{~s}$ on a cycle or arm crank ergometer (Chia et al., 1997). The WAnT is a test commonly used in rehabilitation and sports for subjects with disabilities. The reliability of this test was validated in many groups i.e. the able-bodied (Inbar et al., 1996), people with physical disabilities (Hutzler et al., 2000; Jacobs et al., 2003; Molik et al., 2005), wheelchair basketball players (Goosey-Tolfrey, 2005; Molik, 2013; Vanlandewijck et al., 1999), individuals with paraand quadriplegia (Jacobs et al., 2003), children, both healthy and with physical disabilities (Tirosh et al., 1990), children with juvenile idiopathic arthritis (Stephens et al., 2007).

Chia et al. (2002) evaluated reliability and variability of the $30 \mathrm{~s}$ Wingate test in a group of boys with intellectual disability and also compared WAnT performance of boys with and without ID. High reliability was noticed for MP and PP at 0.95 and 0.93 , respectively, for boys with ID and 0.97 and 0.90 for peers without ID. That study showed that boys with ID had comparable levels of reliability in the WAnT to boys without ID, however, the data was more variable in the disabled group. The authors were not certain whether the variability in the WAnT power test was due to a lack of motivation on the part of the boys with ID, or it was the reason of high intensity exercise outcomes in boys with ID.
It has been reported that WAnT performance in special populations is not only inferior to those of normal populations, but also more variable (Inbar et al., 1996).

Results of previous studies did not clearly indicate which laboratory and non-laboratory (field) tests should be used to assess short-term efforts of people with intellectual disabilities. The Wingate test was very rarely used in studies in people with ID. Thus, the aim of the present study was to evaluate laboratory and field-based tests of short time effort with maximal intensity in people with intellectual disability.

\section{Material and Methods}

\section{Participants}

Twenty-four subjects with ID aged 18-30 years volunteered to participate in this study. Adult Special Olympics athletes composed the research sample. All subjects agreed to participate in the study by signing the consent form. The study was conducted during the Special Olympics training camp in the Olympic Sports Centre in Spała (Poland), between the $9^{\text {th }}$ and $15^{\text {th }}$ of May, 2014. All study participants were classified as having moderate ID. Subjects with Down Syndrome did not participate in the study. The average age, body height, body mass, and BMI were: 22.46 years $(\mathrm{SD}=3.84), 171.08 \mathrm{~cm}(\mathrm{SD}=8.57)$, $71.54 \mathrm{~kg}(\mathrm{SD}=13.09)$ and $24.39 \mathrm{~kg} / \mathrm{m}^{2}(\mathrm{SD}=3.87)$, respectively.

The participants were informed about the possibility to withdraw from the research at any time. None of the subjects resigned from participation. Inclusion criteria for the subjects to participate were as follows: intellectual disability without any other dysfunction, without any cardiorespiratory or pulmonary diseases.

\section{Measures}

A weight scale $(\mathrm{kg})$ and a stadiometer $(\mathrm{cm})$ were used for anthropometric measurements. The laboratory tests consisted of the $8 \mathrm{~s}$ and $30 \mathrm{~s} \mathrm{WAnT} \mathrm{(Inbar} \mathrm{et} \mathrm{al.,} \mathrm{1996;} \mathrm{Chia} \mathrm{et}$ al., 2002; Guerra, 2009). The tests were conducted on a Monark cycle ergometer (Ergomedic 874E) interfaced with a computer. For the selection of the most optimal resistance to use during the basic test (30 s), pre-tests were performed for all participants. During the pre-tests, peak power (PP) was monitored and the time at which it was achieved. The resistance load, with which the best 
values of PP were registered, was applied during the $30 \mathrm{~s}$ WAnT.

The field-based tests were conducted on a synthetic track. Most of the non-laboratory tests derived from selected tests from the Eurofit test battery or the International Physical Fitness Test. The participants performed 9 tests: 5,10 and $20 \mathrm{~m}$ sprints, a $20 \mathrm{~m}$ shuttle run in $30 \mathrm{~s}$, sit-ups in $30 \mathrm{~s}$, a seated medicine ball throw $(3 \mathrm{~kg})$ with both hands from the chest, bent arm hang on a bar, a standing broad jump using two foot take-off and landing and a hand grip test $(\mathrm{kg})$. Each subject completed the tests individually. The examiner verbally encouraged participants during tests, but was not allowed to help in any other way.

\section{Procedures}

The subjects participated in four sessions of measurement. The first one was the laboratory testing, i.e. anthropometric measurements and pre-tests. As a pre-test, $8 \mathrm{~s}$ cycling with maximal speed was used and it was conducted in groups of five people. After a warm-up, i.e. $2 \mathrm{~min}$ of pedalling between 50-60 rpm, they stopped and started the pre-test with $3 \%$ of their body mass. The load increased by $1 \%$ in each following trial. After this short exercise, the participant rested until his heart rate (HR) decreased to the resting level, and then he performed a trial with higher resistance. The participants continued performing $8 \mathrm{~s}$ tests until they could not achieve higher PP. If a subject reached $0.74 \mathrm{~N}$ per kilogram of body mass, he would not continue the pre-tests. Each of them was allowed a maximum of five trials. The participants were verbally encouraged throughout the tests. During the $8 \mathrm{~s}$ tests the subjects went through the familiarization process. These trials were helpful in teaching the participants the correct execution of the exercise. After establishing the most adequate load for each of the participants, they repeated the $8 \mathrm{~s}$ test the second time (with the same load).

In the second session, the standardized 30 s WAnT was performed (Inbar et al., 1996 ). The session consisted of a warm-up (pedalling for 5 $\mathrm{min}$ at $60 \mathrm{rpm}$ and load 50W), 2-3 min of rest, the $30 \mathrm{~s} \mathrm{WAnT}$ and a cool down (pedalling for $2 \mathrm{~min}$ ). The test was started after a countdown of " $3,2,1$, go", and then, the participant began pedalling on the ergometer at maximum speed and continued for $30 \mathrm{~s}$. During the WAnT, mean power (MP), relative mean power (rMP - power per kilogram of body mass), peak power (PP), relative peak power (rPP - power per kilogram of body mass), and the fatigue index (FI - determined on the basis of power decline) were measured.

The third session was conducted one day after the second day of testing. The participants repeated the $30 \mathrm{~s}$ WAnT, step by step like in the previous session.

The fourth session included the fieldbased measurements to assess participants' physical fitness and abilities. The tests consisted of a handgrip test (dynamometer), track events (5, 10 and $20 \mathrm{~m}$ sprints), a $20 \mathrm{~m}$ shuttle run test, a standing broad jump, sit-ups in $30 \mathrm{~s}$, a modified seated medicine ball throw $(3 \mathrm{~kg})$, and the bent arm hang test.

Each subject completed all tests. The participants of the study performed the tests under similar conditions, and were verbally encouraged during tests. The same examiner conducted all tests for all subjects.

\section{Statistical analysis}

All statistical analyses were performed using IBM SPSS Statistics 21. The Pearson correlation coefficient was used to assess the level of reliability of laboratory anaerobic tests, and to determine the relationships between anaerobic performance parameters and all field tests. An alpha value of $p<.05$ was considered statistically significant.

\section{Results}

The mean values, standard deviations, minimum and maximum values for all the test variables are presented in Table 1.

The reliability of the $30 \mathrm{~s}$ and $8 \mathrm{~s}$ WAnT was confirmed. The results for the reliability of two trials of the $30 \mathrm{~s}$ Wingate test showed a significant correlation level between the tests (MP .97; rMP .91; PP .97; rPP .88; FI .88). In the $8 \mathrm{~s}$ Wingate test the correlations were lower in comparison to the $30 \mathrm{~s}$ WAnT, but also high (MP .68; rMP .66; PP .75; rPP .76). The results revealed that subjects with ID reached high reliability in anaerobic tests.

The correlations between the $30 \mathrm{~s}$ and $8 \mathrm{~s}$ Wingate tests and all field tests are summarized in Table 2. The $30 \mathrm{~s}$ WAnT correlated with the handgrip test (MP, rMP, PP), the $20 \mathrm{~m}$ shuttle run (rPM, rPP), the medicine ball throw (MP, rMP, PP, $\mathrm{rPP}$ ) and bent arm hang tests (MP, rMP). The $8 \mathrm{~s}$ WAnT correlated with the $20 \mathrm{~m}$ shuttle run (rMP, 
rPP), the broad jump (all parameters) and sit-up tests (rMP). Strongest correlation was indicated between MP and PP measured in the $30 \mathrm{~s}$ WAnT and the medicine ball throw test $(\mathrm{r}=.642$ and $\mathrm{r}=$ .659 , respectively). The strongest correlation between MP and PP measured in the $8 \mathrm{~s}$ WAnT was found for the medicine ball throw test $(\mathrm{r}=$ .655 and $r=.668$, respectively).
Table 3 demonstrates the correlations between the two short-term exercise tests ( $30 \mathrm{~s}$ and $8 \mathrm{~s}$ ) in measured values. The correlations between the tests are statistically significant in mean power, relative mean power, maximum power and maximum relative power.

Table 1

Values of the $30 \mathrm{~s}$ and $8 \mathrm{~s}$ Wingate tests and field-based tests of subjects with intellectual disability

\begin{tabular}{|c|c|c|c|c|c|}
\hline & VARIABLE & MEAN & SD & MIN & MAX \\
\hline \multirow{9}{*}{ 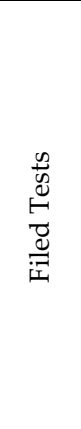 } & Handgrip & 78.05 & 20.55 & 48.00 & 131.00 \\
\hline & $5 \mathrm{~m}$ sprint & 1.70 & 0.23 & 1.24 & 2.27 \\
\hline & $10 \mathrm{~m}$ sprint & 2.59 & 0.26 & 2.20 & 3.30 \\
\hline & $20 \mathrm{~m}$ sprint & 4.25 & 0.41 & 3.70 & 5.20 \\
\hline & $\begin{array}{l}20 \text { m shuttle } \\
\text { run }\end{array}$ & 125.48 & 10.34 & 106.00 & 140.00 \\
\hline & Broad jump & 1.74 & 0.31 & 1.17 & 2.35 \\
\hline & Ball throw & 5.02 & 0.72 & 4.00 & 6.50 \\
\hline & Sit-ups & 19.21 & 4.62 & 10.00 & 29.00 \\
\hline & Bent arm hang & 27.45 & 17.38 & 7.98 & 72.12 \\
\hline \multirow{5}{*}{$\begin{array}{l}\vec{E} \\
\sum_{4} \\
3 \\
\infty \\
0 \\
\infty \\
1 \\
\frac{1}{n}\end{array}$} & MP30_1 & 458.14 & 121.39 & 286.90 & 868.20 \\
\hline & rMP30_1 & 6.41 & 1.06 & 4.43 & 8.28 \\
\hline & PP30_1 & 606.88 & 181.26 & 330.10 & 1229.20 \\
\hline & rPP30_1 & 8.45 & 1.58 & 5.00 & 11.38 \\
\hline & FI30_1 & 18.17 & 12.74 & 0.06 & 37.18 \\
\hline \multirow{5}{*}{ 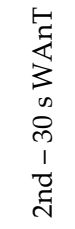 } & MP30_2 & 445.75 & 117.82 & 289.50 & 870.50 \\
\hline & rMP30_2 & 6.21 & 1.11 & 3.90 & 8.32 \\
\hline & PP30_2 & 585.13 & 180.49 & 329.10 & 1234.10 \\
\hline & rPP30_2 & 8.07 & 1.70 & 3.46 & 11.21 \\
\hline & FI30_2 & 18.22 & 12.02 & 0.10 & 35.26 \\
\hline \multirow{4}{*}{ 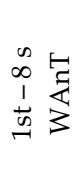 } & MP8_1 & 412.13 & 150.74 & 142.20 & 680.39 \\
\hline & rMP8_1 & 5.78 & 1.95 & 2.49 & 8.72 \\
\hline & PP8_1 & 539.77 & 188.30 & 210.60 & 872.80 \\
\hline & rPP8_1 & 7.58 & 2.44 & 3.69 & 11.32 \\
\hline \multirow{4}{*}{ 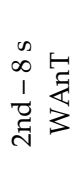 } & MP8_2 & 483.67 & 141.42 & 220.00 & 784.80 \\
\hline & rMP8_2 & 6.70 & 1.48 & 3.86 & 9.33 \\
\hline & PP8_2 & 612,72 & 170.08 & 320.70 & 919.10 \\
\hline & rPP8_2 & 8.50 & 1.79 & 5.63 & 11.56 \\
\hline
\end{tabular}

The first trial of the $30 \mathrm{~s}$ Wingate test: MP30_1 - mean power, rMP30_1 - relative mean power, PP30_1 - peak power, rPP30_1 - relative peak power,

FI30_1-fatigue index. The first trial of the $8 \mathrm{~s}$ Wingate test:

MP8_1-mean power, rMP8_1-relative mean power, PP8_1-peak power and rPP8_1 - relative peak power. The second trial of the $30 \mathrm{~s}$ Wingate test: MP30_2 - mean power, rMP30_2 - elative mean power, PP30_2 - peak power, rPP30_2 - relative peak power, FI30_2 - fatigue index.

The second trial of the $8 \mathrm{~s}$ Wingate test: MP8_2 - mean power, rMP8_2 - relative mean power, PP8_2 - peak power, rPP8_2 - relative peak power. 
Table 2

Correlations between the $30 \mathrm{~s}$ and $8 \mathrm{~s}$ tests and all field tests

\begin{tabular}{|c|c|c|c|c|c|c|c|c|c|c|}
\hline & & MP30 & rMP30 & PP30 & rPP30 & FI30 & MP8 & rMP8 & PP8 & rPP8 \\
\hline \multirow{2}{*}{ Handgrip } & $\mathrm{R}$ & $.618^{* *}$ & $.481^{*}$ & $.545^{*}$ & .420 & .148 & .277 & .070 & .255 & .035 \\
\hline & $\mathrm{P}$ & .005 & .037 & .016 & .074 & .544 & .252 & .775 & .293 & .885 \\
\hline \multirow{2}{*}{$5 \mathrm{~m}$ sprint } & $\mathrm{R}$ & -.167 & -.325 & -.173 & -.327 & $-.407^{*}$ & -.086 & -.143 & -.082 & -.142 \\
\hline & $\mathrm{P}$ & .435 & .121 & .419 & .119 & .048 & .690 & .504 & .703 & .507 \\
\hline \multirow{2}{*}{$10 \mathrm{~m}$ sprint } & $\mathrm{R}$ & -.213 & -.376 & -.183 & -.330 & -.097 & -.324 & -.383 & -.327 & -.380 \\
\hline & $\mathrm{P}$ & .317 & .070 & .391 & .115 & .652 & .122 & .065 & .119 & .067 \\
\hline \multirow{2}{*}{$20 \mathrm{~m}$ sprint } & $\mathrm{R}$ & -.341 & -.302 & -.292 & -.248 & -.001 & -.405 & -.345 & -.380 & -.305 \\
\hline & $\mathrm{P}$ & .153 & .209 & .226 & .305 & .997 & .085 & .148 & .108 & .204 \\
\hline \multirow{2}{*}{$\begin{array}{l}20 \text { m shuttle } \\
\text { run }\end{array}$} & $\mathrm{R}$ & .159 & $.587^{* *}$ & .156 & $.547^{* *}$ & .026 & .409 & $.597^{* *}$ & .409 & $.599^{* *}$ \\
\hline & $\mathrm{P}$ & .469 & .003 & .477 & .007 & .907 & .052 & .003 & .052 & .003 \\
\hline \multirow{2}{*}{ Broad jump } & $\mathrm{R}$ & .134 & .305 & .159 & .345 & .116 & $.539^{* *}$ & $.601^{* *}$ & $.565^{* *}$ & $.626^{* *}$ \\
\hline & $\mathrm{P}$ & .533 & .148 & .459 & .099 & .589 & .007 & .002 & .004 & .001 \\
\hline \multirow{2}{*}{ Ball throw } & $\mathrm{R}$ & $.642^{* *}$ & $.485^{*}$ & $.659^{* *}$ & $.580^{* *}$ & .096 & $.655^{* *}$ & $.475^{*}$ & $.668^{* *}$ & $490^{*}$ \\
\hline & $\mathrm{P}$ & .001 & .022 & .001 & .005 & .670 & .001 & .025 & .001 & .021 \\
\hline \multirow{2}{*}{ Sit-ups } & $\mathrm{R}$ & .018 & .369 & -.043 & .247 & .001 & .231 & $.416^{*}$ & .166 & .344 \\
\hline & $\mathrm{P}$ & .935 & .076 & .842 & .245 & .997 & .277 & .043 & .439 & .100 \\
\hline \multirow{3}{*}{$\begin{array}{l}\text { Bent arm } \\
\text { hang }\end{array}$} & $\mathrm{R}$ & $.566^{*}$ & $.574^{*}$ & .400 & .398 & -.012 & .021 & -.004 & -.064 & -.098 \\
\hline & $\mathrm{P}$ & 018 & 016 & .111 & .114 & .962 & .938 & .988 & .808 & 708 \\
\hline & $\begin{array}{l}P \\
\text { for }\end{array}$ & $\begin{array}{l}05 ;{ }^{* *} \\
0-p e a \\
\text { e } 30 \text { s } \\
\text { P8-ped }\end{array}$ & $\begin{array}{l}\text { o1; } \\
\text { wer, } r \\
\text { AnT; } 1 \\
\text { ower, }\end{array}$ & $\begin{array}{l}\text { 30-me } \\
\text { 30-rel } \\
\text { 8-mea } \\
\text { 8-relo }\end{array}$ & $\begin{array}{l}\text { e peak } \\
\text { ower, } \\
\text { e peak }\end{array}$ & $\begin{array}{l}\text { ower, } \\
\text { AP8-r } \\
\text { ower }\end{array}$ & $\begin{array}{l}\text { I30-fa } \\
\text { ative } \\
\text { the } 8\end{array}$ & $\begin{array}{l}\text { mean } \\
\text { que ind } \\
\text { WAn por } \\
\text { WAn }\end{array}$ & & \\
\hline
\end{tabular}

Table 3

Correlations between the $30 \mathrm{~s}$ and $8 \mathrm{~s}$ Wingate tests

\begin{tabular}{lccccc}
\hline & & MP8 & rMP8 & PP8 & rPP8 \\
\cline { 3 - 6 } MP30 & $\mathrm{r}$ &. $\mathbf{4 8 6}$ & .217 &. $\mathbf{4 3 2}$ & .162 \\
& $\mathrm{p}$ & .016 & .309 & .035 & .450 \\
rMP30 & $\mathrm{r}$ & .371 &. $\mathbf{4 6 9}$ & .324 &. $\mathbf{4 3 0 ^ { * }}$ \\
& $\mathrm{p}$ & .075 & .021 & .123 & .036 \\
PP30 & $\mathrm{r}$ & $.458^{*}$ & .185 &. $\mathbf{4 4 2}$ & .170 \\
& $\mathrm{p}$ & .025 & .387 & .031 & .428 \\
rPP30 & $\mathrm{r}$ & .386 &. $\mathbf{4 2 0}$ & .397 &. $\mathbf{4 4 0}$ \\
& $\mathrm{p}$ & .062 & .041 & .055 & .032 \\
FI30_1 & $\mathrm{r}$ & -.217 & -.332 & -.076 & -.185 \\
& $\mathrm{p}$ & 308 & .113 & .725 & .388 \\
\hline
\end{tabular}

${ }^{*} p<0.05 ;$ MP30-mean power, rMP30-relative mean power, PP30-peak power,

rPP30 relative peak power for the $30 \mathrm{~s}$ WAnT; MP8-mean power,

rMP8-relaitve mean power, PP8-peak power,

rPP-relative peak power for the $8 \mathrm{~s} W A n T$. 


\section{Discussion}

All participants of this study had moderate intellectual disability (Luckasson and Reeve, 2001). Some studies demonstrated that people with ID had higher levels of body fat than their peers without ID (Yamaki and Taylor, 2005). In the present study, subjects with ID had a BMI value of 22.46, i.e. in normal weight status. Freedman et al. (2010) reported that the BMI of able-bodied men (mean age=30, n=1427) was 26.5. Subjects of this study, who were males with ID, were leaner than their peers without disability in the Freedman et al.'s (2010) study.

The aim of the study was to evaluate laboratory and field-based tests of short-term effort with maximal intensity in subjects with intellectual disabilities. The reliability coefficients in the $30 \mathrm{~s}$ WAnT of the active men with ID were high for MP, rMP, PP and rPP at 0.97, 0.91, 0.97 and 0.88 , respectively, and comparable to the results of young men without ID (Inbar et al., 1996) as well as adolescents with ID (Chia et al., 2002). The level of reliability of the $8 \mathrm{~s}$ WAnT was lower in comparison to the $30 \mathrm{~s}$ WAnT. Results confirmed reliability of both tests, however, further analyzes of shorter tests based on the phosphagen system are recommended.

In this study, the reliability of the fatigue index (FI) in the $30 \mathrm{~s}$ test-retest was at a high level $(\mathrm{p}<.05$, FI 0.88). In other research the authors indicated a low level in relative and absolute reliability of the FI for the 20 and $30 \mathrm{~s}$ test duration in a group without disabilities (Attia et al., 2014). The reliability of this parameter requires further studies to confirm the results.

However, the reliability of the $30 \mathrm{~s}$ Wingate test in people with intellectual disability with Down syndrome is questionable (Guerra et al., 2009). The research showed statistically significant difference only in PP values (0.93, $p<.05)$ and the authors suggested that more practice or more tests might be needed to receive reliable results in this group of disability. Perhaps if the testing time was shortened, the reliability coefficient would be higher. Reliability of the $20 \mathrm{~s}$ Wingate test was determined for the abled-bodied (Attia et al., 2014) and disabled group (Dallmeier et al., 2012). Attia et al. (2014) demonstrated that the $20 \mathrm{~s}$ WAnT was a reliable tool for evaluation of anaerobic performance of legs in male team sport athletes, while Dallmeier et al. (2012) showed that the test-retest reliability of mean power output was excellent $(0.96, p<.05)$ and the peak power output was lower, but still reliable $(0.85, p<.05)$ in children with cerebral palsy.

In the current study throughout every trial examiner verbally encouraged participants to put maximal effort into the $30 \mathrm{~s}$ test. High correlation coefficients in the $30 \mathrm{~s}$ WAnT indicated no motivation problem to perform the task by subjects with ID. However, in literature behavioral difficulties of people with ID were noted (Cromarck et al., 2000). More studies concerning this issue are necessary to solve the problem.

Significant relationships between the values of Wingate tests and filed-based tests indicate that field tests are a good tool for Special Olympics coaches or occupational therapists to evaluate non-laboratory anaerobic performance of people with ID. The strongest correlation was observed in the seated medicine ball throw from the chest and values of MP, rMP, PP, rPP in $8 \mathrm{~s}$ and 30 s tests; other tests had lower but significant correlations in the hand grip test and MP30, rMP30, PP30; the $5 \mathrm{~m}$ sprint and FI30; the $20 \mathrm{~m}$ shuttle run and rMP30, rPP30, rMP8, rPP8; sit-ups and rPM8; the bent arm hang test and MP30, rMP30. The results indicated that the medicine ball throw correlated most strongly with laboratory tests. Other research presented similar results (Molik et al., 2013), where the strongest correlation was revealed between MP, PP, and the field test measuring the two-handed chest pass of female wheelchair basketball players. Vanlandewijck et al. (1999) demonstrated a high correlation between the shuttle run and the anaerobic laboratory test (arm cranking) in wheelchair basketball players. Among the other field tests, the shuttle run test is a reliable and valid tool for examining anaerobic capacity and skill proficiency assessment in wheelchair basketball players. No information about this issue in people with intellectual disability was found in the literature.

The outcomes of this study did not confirm the assumption that the $8 \mathrm{~s}$ and $30 \mathrm{~s}$ WAnT would be highly correlated. Although the correlations were significant, the values were on a moderate level i.e. 0.49, 0.47, 0.44 and 0.44 for MP, rMP, PP and rPP, respectively. The results showed that the $8 \mathrm{~s}$ test could be used as an 
alternative to the $30 \mathrm{~s}$ Wingate test. Although further investigations are needed to confirm or discard this finding. Similar analyzes were performed in able-bodied competitive athletes. Zając et al. (1999) reported that the $10 \mathrm{~s}$ version of the Wingate test can be used for evaluation of maximal power. Our analyzes confirmed the results of previous studies. Shorter tests ( 8 or $10 \mathrm{~s}$ ) are based on the phosphagen system and induce maximal power in people with and without disabilities. The longer $(30 \mathrm{~s})$ test is a good predictor for evaluation of the effectiveness of the glycolic system. Mean power is a good indicator of the effectiveness of submaximal efforts for prolonged time i.e. 15-20 s (Zając et al., 1999). Anyway, Zając et al. (2013) reported higher results of the $10 \mathrm{~s}$ WAnT in comparison to the $30 \mathrm{~s}$ WAnT. We are not able to confirm previous investigations' findings due to differences in the 8 s WAnT between first and second tests. However, in the second $8 \mathrm{~s}$ WAnT individuals achieved better results of peak power and mean power in comparison to the $30 \mathrm{~s}$ WAnT.

Further research regarding this matter is recommended primarily in untrained subjects with intellectual disability and with Down syndrome where the results are not clear. It seems justified to shorten the time of the WAnT to 15, 10 or $8 \mathrm{~s}$ to achieve greater reliability in subjects with ID.

\section{Conclusion}

The two tests of 8 and $30 \mathrm{~s}$ can be used to evaluate short-term efforts with maximum intensity in people with intellectual disabilities (without Down syndrome). The medicine ball throw seems to be the best test to indirectly (non-laboratory) evaluate muscular power of subjects with intellectual disability.

\section{References}

Attia A, Hachana Y, Chaabène H, Gaddour A, Neji Z, Shephard RJ, Chelly MS. Reliability and validity of a 20-s alternative tot he Wingate anaerobic test in team sport male athletes. Plos One, 2014; 9(12): e114444

Baynard T, Pitetti KH, Guerra M, Unnithan VB, Frnhall B. Age-Related Changes in Aerobic Capacity in Individuals with Mental Retardation: A 20-yr Review. Med Sci Sports Exerc, 2008; 40(11): 1984-1989

Blomqvist S, Wester A, Sundelin G, Rehn B. Test-retest reliability, smallest real difference and concurrent validity of six different balance tests on young people with mild to moderate intellectual disability. Physiother, 2012; 4(98): 318-324

Chia YHM, Lee KS, Teo-Koh SM. High intensity performances of boys with and without intellectual disability. J Intelectl Dev Dis, 2002; 3: 191-200

Chia M, Armstrong N, Childs D. The assessment of children's anaerobic performance using modifications of the Wingate Anaerobic Test. Pediatr Exerc Sci, 1997; 9: 80-89

Cormark KFM, Brown AC, Hastings RP. Behavioral and emotional difficulties in students attending schools for children and adolescents with severe intellectual disability. J Intell Disabil Res, 2000; 44: 124-129

Dallmeijer A, Scholtes V, Brehm M, Becher J. Test-retest reliability of the 20-sec Wingate test to assess anaerobic power in children with cerebral palsy. Am J Phys Med Rehabil, 2012; 6: 1537-7385

Fernhall B, Pitetti KH. Leg strength is related to endurance run performance in children and adolescents with mental retardation. Pediatr Exerc Sci, 2000; 12: 324-333

Fernhall B, Pitetti KH. Limitations to physical work capacity in individuals with mental retardation. Clin Exerc Phys, 2001; 3(4): 176-185

Freedman DS, Katzmarzyk PT, Dietz WH, Srinivasan SR, Berenson GS. The relation of BMI and skinfold thicknesses to risk factors among young and middle-aged adults: the Bogalusa Heart Study. Ann of Hum Biol, 2010; 37(6): 726-737

Frey GC. Comparison of physical activity levels between adults with and without mental retardation. J Phys Act Health, 2004; 1: 235-245

Goosey-Tolfrey V. Physiological profiles of elite wheelchair basketball players in preparation for the 2000 Paralympic Games. Adapt Phys Activ Q, 2005; 22: 57-66

Guerra M, Gine-Garriga M, Fernhall B. Reliability of Wingate Testing in Adolescents with Down Syndrome. Pediatr Exerc Sci, 2009; 21: 47-54 
Guerra BM, Cuadrado ME, Geronimo BC, Ferenhall Bo. Physical Fitness Levels of Physically Active and Sedentary Adults With Down Syndrome. Adapt Phys Activ Q, 2000; 17(3): 310-321

Horvat M, Croce R, Pitetti KH, Fernhall B. Comparison of isokinetic peak force and work parameters in youth with and without mental retardation. Med Sci Sports Exerc, 1999; 31(8): 1190-1195

Hutzler Y, Vanlandewijck Y, Vlierberghe M. Anaerobic performance of older female and male wheelchair basketball players on a mobile wheelchair ergometer. Adapt Phys Activ Q, 2000; 17: 450-465

Inbar O, Bar-Or O, Skinner J. The Wingate Anaerobic Test. Campaign, IL: Human Kinetics; 1996

Jacobs P, Mahoney E, Johnson B. Reliability of arm Wingate anaerobic testing in persons with complete tetraplegia. J Spinal Cord Med, 2003; 26: 141-144

Jin-Ding L, Pei-Ying L, Lan-Ping L, Yu-Yu Ch, Sheng-Ru W, Jia-Ling W. Physical Activity and Its Determinants among Adolescents with Intellectual Disabilities. Res Dev Disabil, 2010; 31(1): 263-269

Luckasson R, Reeve A. Naming, defining, and classifying in mental retardation. Ment Retard, 2001; 39: 47-52

Molik B, Kosmol A, Rutkowska I. Anaerobic performance as a criterion in classifying wheelchair basketball players. Movement and Health $4^{\text {th } I n t e r n a t i o n a l ~ C o n f e r e n c e, ~ P r o c e e d i n g s ~(A b s t r a c t ~ a n d ~ f u l l ~ p a p e r s) . ~}$ Olomuc, November 23-25, CD-ROM; 2005

Molik B, Laskin JJ, Kosmol A, Marszałek J, Morgulec-Adamowicz N, Frick T. Relationships between anaerobic performance, field tests, and functional level of elite female wheelchair basketball athletes. Hum Mov, 2013; 14(4): 366-371

Pitetti KH, Baynard T, Agiovlasitis S. Children and adolescents with Down syndrome, physical fitness and physical activity. J Sport Health Sci, 2012; 2(1): 47-57

Pitetti KH, Boneh S. Cardiovascular fitness as related to leg strength in adults with mental retardation. Med Sci Sports Exerc, 1995; 27(3): 423-428

Pitetti KH, Fernhall B, Stubbs N, Stadler Jr LV. A Step Test for Evaluating the Aerobic Fitness of Children and Adolescents With Mental Retardation. Pediat Exerc Sci, 1997; 9(2): 127-136

Tirosh E, Bar-Or O, Rosenbaum P. New muscle power test in neuromuscular disease. Am J Dis Child, 1990; 144: 1083-1087

Vanlandewijck Y, Daly D, Theisen D. Field teest evaluation of aerobic, anaerobic, and wheelchair basketball skill performance. Int J Sports Med, 1999; 2: 548-554

Stephens S, Singh-Grewal D, Bar-Or O, Beyene J, Cameron B, Leblanc CM, Schneider R, SchneidermanWalker J, Selvadurai H, Silverman E, Spiegel L, Tse SM, Wright V, Feldman BM. Reliability of exercise testing and functional activity questionnaires in children with juvenile arthritis. Arthritis Rheum, 2007; 15(57, 8): 1446-1452

Wondra VC, Pitetti KH, Yarmer DA. Fitness profiles of males 8-18 years with and without mental retardation. Med Sci Sports Exerc, 2000; 32: 1273

Yamaki K, Taylor SJ. Body Weight Status among Adults with Intellectual Disability in the Community. Ment Retard, 2005; 43(1): 1-10

Yarmer DA, Pitetti KH, Wondra VC. Fitness profiles of females 8-18 years with and without mental retardation. Med Sci Sports Exerc 2000; 32: 1272

Zając A, Jarząbek R, Waśkiewicz Z. The Diagnostic Value of the 10 and 30 s Wingate Test for Competetive Athletes. J Strength Cond Res, 1999; 13(1): 16-19

\section{Corresponding author:}

\section{Judit Lencse - Mucha}

Department of Sport for People with Disabilities, Faculty of Physiotherapy

Józef Piłsudski University of Physical Education in Warsaw, Poland,

34 Marymoncka Street, 00 - 968 Warszawa,

Phone: +48607225448, Fax: +48 22 8354798,

E-mail: judit.mucha@awf.edu.pl 